\title{
The study of design problem in design thinking
}

\author{
Y.-c. Chiang \\ Chaoyang University of Technology, Taiwan
}

\begin{abstract}
The view of design as a kind of problem-solving activity has been an important base in the study of design cognition. Most of time, the researchers identify design problems as design briefs. But recently, some results of protocol analysis have implicated that design problems are not only about the briefs and need not exist at the beginning of design. This paper studied the roles of design problems in design thinking by protocol analysis. The results show that there are two kinds of problems which occur in the design process: one is related to the brief, and the other is about designer's intention. The advanced study has been focused on the differences of the thinking mechanisms of these two kinds of problem.

Keywords: design problem, design thinking, design cognition, protocol analysis.
\end{abstract}

\section{Introduction}

For a long time, design has been regarded as a kind of problem-solving activity. From the early researches on design methods and methodologies to the lateral design cognition studies, this viewpoint has been the common base. What is more, design problem is defined as the brief of design, which is usually induced to the functional requirements. However, some results of protocol analyses have showed that design problems are not only about the briefs and need not to exist at the beginning of design. These phenomena indicate that the contents and meanings of design problems in real design are different from what the problemsolving theory has claimed. The former is some kind of fact from thinking report, and the later is determined by definition. Not from a prescriptive consideration but a phenomenon study, this paper aims to clarify the differences so as to investigate the thinking characteristics of design problems. 


\section{Design problems in problem-solving theory}

Many researchers have pointed to the properties that separate simple and welldefined problems from complex and ill-defined ones. Both Reitman [6] and Simon [7] discuss the nature of ill-defined problems in detail. But the criteria Simon suggests for well-structured problems are still vague. And Akin [1] considered the properties of design what constitutes the "ill-defined". When they discuss the definitions or structures of design problems, they describe the incompleteness of requirements of client, from which the ill definition of problem space is deduced.

The typical point of view regards design problems as design briefs and has spurred many researchers on to study the functional problems, which are always the major topic in design briefs. These efforts focused on improvement of design methods and reasoning in dealing with complex briefs, such as the research of architecture planning. And Alexander's research (1962) is another kind. He combined the functional and formal facets of design to decompose a huge and complicated structure - an Indian village into some hierarchical small units. He tried to advance design problem solving by decomposing a big problem into some sub-problems. These researches look for to overcome the ambiguity of design problems specified in design briefs.

Some characteristics of design problems in problem-solving theory can be collected as follows:

1. Design problems are regarded as the content of client briefs, which describe the goal of design, and especially as functional requirements.

2. The informational completeness is major concern for problem space definition. This incompleteness makes most of real world problems to belong to ill-structured problems.

3. The position that the problem-solving theory considers problems is for artificial intelligence, but not necessary for human designers. And most of the definitions or criteria are established for the convenient to the computational ability of a problem-solving system, which is always referred to computers but not human beings. It is a kind of prescriptive discussion on problems in the theory of problem solving.

\section{Research issues}

These prescriptive notions of design problems have led the developments of artificial intelligence, but also result in some lost when they are extended to represent characteristics of human thinking. From some design protocols recorded in the precedent research (Chiang and Wang, [2]), when designers reported their problems in design processes, they talked about some contents, which really baffled them, different from the briefs. So what is the nature of these differences? Does it mean any different meaning of thinking? To answer these questions it needs to study design problems from human thinking.

In order to improve the understanding the characteristics of design problems in design thinking, the close studies of real-word design process could offer 
several critical discoveries. Lawson (Lawson [5]) points out some important characteristics of design problems after many observations of designers at work. He mentions that design problems cannot be comprehensively stated, require subjective interpretation, and tend to be organized hierarchically. Comparatively speaking, Lawson concerns more about the actual way in which designers think, and has observed the impossibility of complete and static formulation of design problems. Although Lawson points out subjectivity in interpretation of design problems, he seems to restrict such subjectivity only coming from domain disciplines.

This paper emphasizes that another more critical factor of subjectivity interpretations on design problem results from designers' intentions, especially in high creative design. This paper differentiates designers' intentions from various design disciplines and methods, and identifies such intentions as a key factor to make design as art. The actual contents of designers' intentions could contain life values, design philosophies, particular preferences and so on, which are usually formed not in particular design courses but as an integrated effect of various experiences and learning. This factor is usually disregarded in the so-call design professional studies, but keeps conducting design implicitly. In design competitions, designers can make various interpretations, and so can form many different design solutions for a common brief. It seems unsatisfactory to explain the variety of competitive solutions induced only from similar professional disciplines. This paper argues that it is designers' intentions that make similar disciplines generate different solutions. And all of these results begin from problem interpretations by designers' intentions, which phenomena could be observed only in empirical studies of design thinking, and is easily ignored in normative discipline studies of design. This paper considers that if design problems are not equal to design briefs, what do they mean in design thinking? And if designers' intentions influence the recognition of real design problems, how do they perform in design?

\section{Two types of protocol analyses}

In the experiments, the aim is to study the differences of designers' cognitions on different definition-degree assignments with individual briefs, which were so called the documents specifying design problems. In the traditional preposition of design problem as design brief, better-defined problems could be expressed as a set of better-defined briefs and so do worse-defined problems. In order to find out the key characteristics of design problem cognition, this research compared design processes of different defined briefs. From the best-defined brief to the worst one, five degrees are classified. This research took design experiments on first four better-defined briefs. This set of experimental designs proceeded in a closed-experimental environment. Another well-defined aspect of experiment is about the design environment. Each design experiment is restricted at one room and during a regulated short period of time.

Comparatively, The worst-defined brief is represented as a real-world design program and has proceeded in an entirely open environment as real world. The 
aim of real-world design protocol is used to investigate the designers' cognitions in open environments and through longer periods. The former well-defined environment controlled designers to design effectively and mostly by knowledge and heuristics. But the later real world as an ill-defined environment, opening these controls to designers themselves, allows something different and uncontrolled to happen. By comparing the cognition of design problems in different-defined design assignments and environments, the common characteristics could be found out. This paper analyzed these two kinds of design protocols individually and comparatively.

\subsection{Experiments on different definition-degree briefs}

\subsubsection{Experiments}

The experiment is composed by four sub-experiments, each with individual design assignment. From better-defined briefs to the worse-defined one, four experimental assignments are "geometry arrangement", "furniture arrangement", "space design", and "architecture design". The subjects were three master-degree architects. They were experimented separately. Table 1 shows the working frame of experiments. These three subjects were asked to draw their designs on the papers and report their design processes as well as their concurrent thinking immediately after the individual sub-experiment. All the verbal reports were translated into scripts. Each statement was numbered as " $\mathrm{X}-\mathrm{Y}$ ", where " $\mathrm{X}$ " is the number of sub-experiment, and "Y" is the order number of the statement in the protocol. The three subjects were coded as "A", "B", and "C".

Table 1: $\quad$ The frame of experiments.

\begin{tabular}{llll} 
Sub-experiments & \multicolumn{1}{c}{ Assignments } & Degrees & Periods \\
\hline $\begin{array}{l}\text { 1. geometry } \\
\text { arrangement }\end{array}$ & $\begin{array}{l}\text { Given a set of geometries, arrange } \\
\text { them into a given space. }\end{array}$ & Best-defined & $20 \mathrm{~min}$. \\
\hline $\begin{array}{l}\text { 2. furniture } \\
\text { arrangement }\end{array}$ & $\begin{array}{l}\text { Given a building structure, functional } \\
\text { requirements and a set of furniture, } \\
\text { arrange furniture into the structure. }\end{array}$ & Well-defined & $20 \mathrm{~min}$. \\
\hline 3. space design & $\begin{array}{l}\text { Given a building structure and III-defined } \\
\text { functional requirements, design the } \\
\text { interior spaces. }\end{array}$ & $20 \mathrm{~min}$. \\
\hline $\begin{array}{l}\text { 4. architecture } \\
\text { design }\end{array}$ & $\begin{array}{l}\text { Given a site and functional Worst-defined } \\
\text { requirements, design the architecture. }\end{array}$ & $30 \mathrm{~min}$. \\
\hline
\end{tabular}

\subsubsection{Results and findings}

Following are results of experimental protocols.

1. In the geometry and furniture arrangement sub-experiments, all three subjects reported what problems they encountered in design processes. The reports of problems occurred not at the beginning but only after a period of design development. For examples:

(C: 1-01) At beginning, I put the pieces by size. The bigger should be placed earlier. And then I felt that there was something wrong. 
(C: 1-06) I began to try from the middle-size piece. But there was a problem of corner.

(A: 2-05) The kitchen puzzled me most, because there was almost no space left for it.

(B: 2-22) Especially the location of the toilet door, it was the first problem I dealt with. I like it not easy to be seen but easy to use.

(C: 2-21) At last, the problem was about the unarranged furniture around the central area. I don't know how to locate them.

2. In the space and architecture design sub-experiments, all three subjects didn't report any statement as problem. But, all of them reported their "wishes", which never occurred in the first two other sub-experiments. These "wishes" sometimes are as clear as a request in (C: 3-31), and sometimes are vague without real contents, such as (B: 3-23) and (B: 4-33). For example:

(A: 3-10) But I wish the space be more fluid.

(B: 3-23) I wish this space (entrance) be special.

(C: 3-31) I wish there will be a window to see the garden.

(B: 4-33) Because it is a literati space, I wish it offered as a special space in architecture.

By analyzing the content of problems, reported as above, there are two findings:

3. The problems, what subjects reported, are not the only content about the requirements, what briefs ask for, but always some "dissatisfactory relations" between requirements and spatial forms. This dissatisfaction seems to be the major factor of problem recognition, and consists in two or more aspects of spatial properties, such as functions, locations, dimensions, views, circumstance, and so on.

4. There are different criteria of evaluation of design: one comes from the requirements, and the other from the subjects' wishes. This finding seems that the evaluative criteria can distinguish the dissatisfactions, so designers could recognize them as problems.

\subsection{Real-world architectural design protocols}

In the study of real-world design practices, which face the open defined problems and are in open environment, the main goals are to reveal the critical thinking characteristics of design problems by which designers were baffled in the extreme. This research has interviewed four real-world designs, in which all of designers once encountered big bottlenecks and finally break through them. Two of these four proceeded in architecture design courses, and the others in architecture practices, one is on design commission and the other is for design competition. These designers separately presented their sketches, design drawings and models and reported their concurrent thinking and doing after a period of time when design has been finished. Compared to think-aloud or retrospection protocols in experiments, there may be some information missed or forgotten in these protocols, but what were remembered must be important and considered well enough for designer to store in memory so as to retrieve. Since 
this type of protocol can filter off the trivial treatments in temporal thinking and leave the influential thinking in memory, it deserves deep study.

\subsubsection{Analyses}

This research coded the whole design protocol into several sequential sections according to the history of designers' reports. Each section is numbered as " 1 ", " 2 ", " 3 "... according to its order. By overall review of each protocol, there are eight factor categories defined to encode the attribution of each statement. These eight factors are classified into three types of divisions: "design premise" as the beginning causes of design, "design thinking" as the thinking body of design, and "the exterritorials" (Ex) containing all information and events outside the territoriality of the preceding design thinking but jumped into design occasionally. In premise division, there are three factors including "design requirements" (abbreviated as "Rq"), "design constraints" (Cs), and "designer intentions" (DI), which are frequently reported. According to the findings of above experimental design protocols, since designers' wishes play an important criterion role as design requirements in the cognition of design problems, it should be the same as requirements in the premise division of whole design thinking. In thinking division, there are four factors including "design problems" (P), "design orientations (Or), "design operations" (Op), and "performance evaluations" (E). These four categories classify the content types of thought described in statements.

By the above encoding system, each statement could be noted by its category abbreviation and sequential number. For example, "P1" represents the statement describing particular design problems in design section 1. There are two purposes of the analysis: one is to find out the factors influencing design problems mostly by the analysis of relation-equations, and the other is to understand the composition of design problem by analyzing its content. For the first purpose, the research analyzed the relationships of design problems with other factors and notes them as relation-equations. For example, "P1=DI1+Rq1.2" means that P1 is related to DI1 and Rq1.2.

For the second purpose, the research designed another notation system to formulate the dissatisfactory relations in design problems, which is revealed in the analyses of experimental design protocols and mentioned in 4.1.2. In the statements designers reported, design problems are always about that something of design were unknown, conflicted with each other, or in bad situation. These "something of design" means the elements of a design problem. And all the unknown, conflict, and bad situation mean various dissatisfactory conditions. In this part of analysis, the contents of design problems are further decomposed into three types of elements, which are "form aspect" representing formal attribution of design contents, "meaning aspect" representing all other attributions of design contents excluding form, and "design operation aspect" representing the information about how to design. The dissatisfactory conditions are judged by the value of element sets. Each type of problem elements has its own criteria, which are guided by the briefs or designers intentions and noted as "F" for form aspect, "M" for meaning aspect, and "O" for design operation aspect. If the 
element set of actual situation is unsatisfied, the research defines that its value is lower than the criterions. For example, "image" $<\mathrm{F}+\mathrm{M}$ " means that the problem element "image" is unsatisfied in its form and meaning aspects. The coding results of design problems in these two systems are shown in Table 2.

Table 2: $\quad$ The analyses of design problems in real-world architectural design protocols.

\begin{tabular}{|c|c|c|c|}
\hline Designers & Problem statements & Relation-equations & $\begin{array}{c}\text { Composition } \\
\text { analyses }\end{array}$ \\
\hline \multirow[t]{5}{*}{ I } & $\begin{array}{l}\text { 1. This project was named 'N. } \\
\text { Y., N. Y.' The client wanted the } \\
\text { building with the image of the } \\
\text { Liberty, but I really cannot } \\
\text { design such. }\end{array}$ & $P 1=D \mid 1+R q 1.2$ & $\begin{array}{l}\text { 'image' }<\mathrm{F}+\mathrm{M} \\
\text { 'cannot design } \\
\text { such'<O/? }\end{array}$ \\
\hline & $\begin{array}{l}\text { 3. He still wished the image of } \\
\text { the Liberty, but we didn't like } \\
\text { to design in post-modern way... }\end{array}$ & P3=DI3+Rq1.2 & $\begin{array}{l}\text { 'the Liberty' }<\mathrm{F}+\mathrm{M} \\
\text { post-modern } \\
\text { way }<\mathrm{O} / \text { ? }\end{array}$ \\
\hline & $\begin{array}{l}\text { 4. After that, we considered a } \\
\text { simpler way to attain the effect } \\
\text { he wanted... }\end{array}$ & P4=D|4+Rq1.2 & $\begin{array}{l}\text { 'a simpler way' }<\mathrm{O} / \text { ? } \\
\text { 'the effect he } \\
\text { wanted' }<\mathrm{F}+\mathrm{M}\end{array}$ \\
\hline & $\begin{array}{l}\text { 5. We reverse this proposal by } \\
\text { ourselves. We returned to think } \\
\text { how to make the form simpler. }\end{array}$ & P5=P4=DI4+Rq1.2 & $\begin{array}{l}\text { 'how' }<\mathrm{O} / \text { ? } \\
\text { 'make the form } \\
\text { simpler' }<\mathrm{F}\end{array}$ \\
\hline & $\begin{array}{l}\text { 7. then I thought of how a glass } \\
\text { curtain-wall can be designed to } \\
\text { express the image. }\end{array}$ & P7=Or6+Rq1.2 & $\begin{array}{l}\text { 'a glass curtain- } \\
\text { wall' }<\mathrm{O} / \text { ? } \\
\text { 'to express the } \\
\text { image' }<\mathrm{F}+\mathrm{M}\end{array}$ \\
\hline \multirow[t]{5}{*}{ II } & $\begin{array}{l}\text { 1.This was a difficult project } \\
\text { because of the lack of site } \\
\text { characteristics. It was an } \\
\text { underground station design. } \\
\text { You can have any expression } \\
\text { only in a few constructions } \\
\text { sticking out the ground. }\end{array}$ & $P 1=R q 1+C s 1+D I 1$ & $\begin{array}{l}\text { 'lack of site } \\
\text { characteristics' }<M / \text { ? } \\
\text { 'have any expression' } \\
<F\end{array}$ \\
\hline & $\begin{array}{l}\text { 2. For a period, I looked for } \\
\text { how to do it? }\end{array}$ & P2=P1+DI2 & $\begin{array}{l}\text { 'how'<O } \\
\text { 'it' }<F / ?\end{array}$ \\
\hline & $\begin{array}{l}\text { 3. It is easy if just to make a } \\
\text { form. But this form will have no } \\
\text { any spirit. I don't know why I } \\
\text { do it. }\end{array}$ & $\begin{array}{l}\text { P3= } \\
D 13.1+D 12+O p 2+E x 2.1\end{array}$ & $\begin{array}{l}\text { 'make a form' }<F \\
\text { 'any spirit',' why I } \\
\text { do it' } \varangle \mathrm{M} / \text { ? }\end{array}$ \\
\hline & $\begin{array}{l}\text { 4. What feel should they evoke? } \\
\text { What image should these } \\
\text { constructions express? }\end{array}$ & $\begin{array}{l}\text { P4= } \\
\text { DI3.1+DI2+DI3.3 }\end{array}$ & $\begin{array}{l}\text { 'feel', 'image' }<M / \text { ? } \\
\text { 'constructions' }<F\end{array}$ \\
\hline & $\begin{array}{l}\text { 7. One night, I thought that } \\
\text { what this form could be } \\
\text { represented as, if the design } \\
\text { concept is "urban festival". }\end{array}$ & $\begin{array}{l}\text { P7 }= \\
\text { Op6.1+Op6.3+DI3.3 }\end{array}$ & $\begin{array}{l}\text { 'what', 'urban festival' } \\
<\mathrm{M} / ? \\
\text { 'this form' }<\mathrm{F} \\
\text { 'represented as' }<\mathrm{O}\end{array}$ \\
\hline
\end{tabular}


Table 2: $\quad$ Continued.

\begin{tabular}{|c|c|c|c|}
\hline \multirow[t]{6}{*}{ III } & $\begin{array}{l}\text { 1.1 I wanted to talk about } \\
\text { American culture and Chinese } \\
\text { culture by design. } \\
1.2 \ldots \text {. . so by the difference of } \\
\text { these two cultures, containing } \\
\text { the varieties of the traditional } \\
\text { and the modern. } \\
1.3 \text {... and there is a changing } \\
\text { from a super culture to a sub- } \\
\text { culture when it migrated. } \\
1.4 \ldots \text {... Io I had been thinking } \\
\text { that how to design an } \\
\text { architecture expressive of these } \\
\text { conflictions of eastern/western } \\
\text { cultures, tradition/modernity, } \\
\text { and super/sub-cultures. }\end{array}$ & $\begin{array}{l}\text { P1.1= Cs1+ DI1 } \\
\text { P1.2< P1.1 } \\
\text { P1.3< P1.1 } \\
\text { P1.4= } \\
\text { P1.1+P1.2+P1.3 }\end{array}$ & $\begin{array}{l}\text { 'culture' } \varangle \mathrm{M} \\
\text { 'the traditional and the } \\
\text { modern' } \varangle \mathrm{M} \\
\text { 'a super culture to a } \\
\text { sub-culture' } \varangle \mathrm{M} \\
\text { 'how to design an } \\
\text { architecture' }<\mathrm{O}+\mathrm{F} / \text { ? } \\
\text { expressive of these } \\
\text { conflictions } \varangle \mathrm{M}\end{array}$ \\
\hline & $\begin{array}{l}\text { 3. What can represent the } \\
\text { culture? }\end{array}$ & P3<P1.4 & $\begin{array}{l}\text { 'what' }<F / ? \\
\text { 'represent' }<\mathrm{O} \\
\text { 'culture' }<\mathrm{M} \\
\end{array}$ \\
\hline & $\begin{array}{l}\text { 4. The most difficulty is how to } \\
\text { express a modern temple in a } \\
\text { complex district, because the } \\
\text { traditional from of temple is too } \\
\text { strong. How to transform it? }\end{array}$ & P4=D|4.2+DI4.1 & $\begin{array}{l}\text { 'express', 'How to } \\
\text { transform' }<\mathrm{O} / \text { ? } \\
\text { 'a modern temple' } \\
<\mathrm{M}+\mathrm{F}\end{array}$ \\
\hline & $\begin{array}{l}\text { 5. It still failed to evoke an } \\
\text { association with a temple, } \\
\text { although it was transformed } \\
\text { from traditional spatial } \\
\text { sequence and characteristics. }\end{array}$ & P5=P4+Op4+DI5 & $\begin{array}{l}\text { 'evoke an association' } \\
\varangle \mathrm{M} \\
\text { 'from', 'spatial } \\
\text { sequence and } \\
\text { characteristics' }<\mathrm{F} / \text { ? } \\
\text { 'transformed' }<\mathrm{O} / \text { ? }\end{array}$ \\
\hline & $\begin{array}{l}\text { 7. I stared to consider the way } \\
\text { of transformation of this fixed } \\
\text { form. }\end{array}$ & P7<P5 & $\begin{array}{l}\text { 'transformation' }<\mathrm{O} / \text { ? } \\
\text { 'this fixed form' }<\mathrm{F}\end{array}$ \\
\hline & $\begin{array}{l}\text { 8. But it was still difficult. So I } \\
\text { still had no idea about how to } \\
\text { do it. }\end{array}$ & P8=P7+Or7 & $\begin{array}{l}\text { 'how to do it' }<\mathrm{O}+ \\
\mathrm{F} / \text { ? }\end{array}$ \\
\hline \multirow[t]{4}{*}{ IV } & $\begin{array}{l}\text { 6. It seemed to need some } \\
\text { transformations of elements. }\end{array}$ & P6 & $\begin{array}{l}\text { 'transformations' } \\
<\mathrm{O} / ? \\
\text { 'elements' }<\mathrm{F}\end{array}$ \\
\hline & $\begin{array}{l}\text { 9.Here occurred a biggest } \\
\text { problem. ...it was the plan of } \\
\text { the four classrooms...at } \\
\text { beginning, the stairs was placed } \\
\text { here for the convenience, but it } \\
\text { became obstacle. }\end{array}$ & P9=Op8.2+DI9 & $\begin{array}{l}\text { 'the stairs' }<F / \text { ? } \\
\text { 'the convenience', } \\
\text { 'obstacle' }<M\end{array}$ \\
\hline & $\begin{array}{l}13 . . . \text { then why should be it? } \\
\text { After lots of tries and errors, } \\
\text { why I still insisted on it? } \\
\end{array}$ & P13=DI10+E12.1 & $\begin{array}{l}\text { 'it (the stairs)' }<\mathrm{F} \\
\text { 'why' }<\mathrm{M} / \text { ? }\end{array}$ \\
\hline & $\begin{array}{l}14 . . . \text { but had no idea about } \\
\text { how to do them (stairs and } \\
\text { obstacles)? }\end{array}$ & P14=P9=Op8.2+D19 & $\begin{array}{l}\text { 'how' }<\mathrm{O} / \text { ? } \\
\text { 'stairs' }<\mathrm{F} \\
\text { 'obstacles' }<\mathrm{M} / \text { ? }\end{array}$ \\
\hline
\end{tabular}




\subsubsection{Results and findings}

1. Two important findings are shown in Table 1 too. One is that all problems consist in two or more types of elements. The other is that there is always an element unknown or unsatisfied, which is noted as "?" in Table 3 in design problem. These phenomena together reveal the recognition of design problem as an unknown or unsatisfied situation within restrictions conducted by designers as well as clients.

2. A summary of the analysis of the amount of occurrences of factors in relation-equations is shown in Figure 1. DI is almost the most frequent influential factor in each protocol, even in the protocol-I, it appeared only one less time than $\mathrm{Rq}$. The result indicates that DI plays a dominant role in the formation of design problem.

3. The main design problems in these real-world protocols all are dominated by designers' intentions. In protocol-I, the designer preferred the simple and abstract form, which was conflicted to client's request of post-modern image. In protocol-II, the designer looked for the proper spirit of form. In protocol-III, the designer searched for the effect method of transformation of traditional temple with its spirit. And in the protocol-IV, the designer struggled with the big problem resulted from his aesthetic preference and insistence on a particular staircase in his preliminary design.

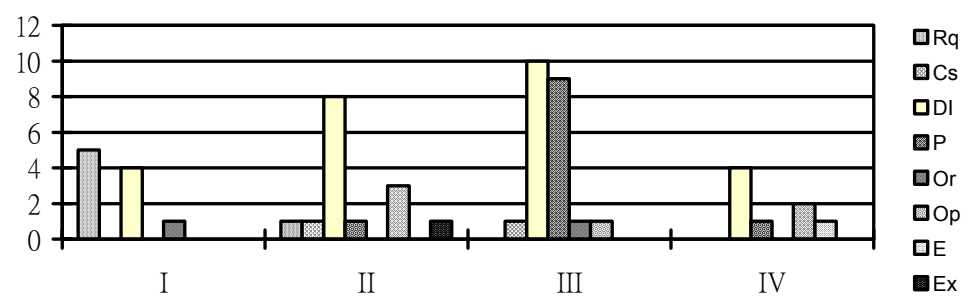

Figure 1: Analysis of appearance times of factors.

\subsection{Comparative analyses}

When a designer deals with these different-degree-defined briefs, is there any different or common recognition characteristic on design problem? What are they? These two questions conducted the comparative analyses of protocols. The comparative analysis of two kinds of design protocols is shown in Table 3 . There are several interesting findings in the cross comparative analysis, shown as follows:

1. Designers didn't reported any design problems in protocol (3) and (4). It seems that design problem needn't occur in designers' thinking actually, even though he is doing design. Will the kind of design thinking this phenomenon indicate be the same to problem solving? It is still a question, which need more investigation.

2. What designers recognize as a design problem is not equal to design brief, since in experimental assignments, like protocol (3) and (4), 
worse-defined briefs didn't result in more problems than betterdefined briefs.

3. The occurrence of designers' intention coincided with the ill-defined assignments. Only when the assignment is open enough, design intention could get a chance to "emerge". There are two reasons this research calls its appearance as "an emerging". One reason is that the intention is always either unclear or unmentioned at beginning, but becomes more and more clear along design process. The other is that the designers' intention is flexible and could be adjusted to different design environments. When the environment, containing its briefs and physical environment, is ill defined, the intention usually dominates the formation of design problem. But when the environment is well defined and restricted, the intention either is not proposed or offers an effective guidance to design development, where it creates particular characters but no problem.

Table 3: Analysis of results of different definition-degree protocols.

\begin{tabular}{|l|c|c|c|c|c|}
\hline $\begin{array}{c}\text { Types of design } \\
\text { protocols }\end{array}$ & $\begin{array}{c}\text { Definition- } \\
\text { degree of } \\
\text { environment }\end{array}$ & $\begin{array}{c}\text { Definition- } \\
\text { degree of } \\
\text { assignment }\end{array}$ & $\begin{array}{c}\text { Designers' } \\
\text { intention } \\
\text { description }\end{array}$ & $\begin{array}{c}\text { Design problem } \\
\text { description }\end{array}$ & $\begin{array}{c}\text { Related } \\
\text { factor of } \\
\text { problem }\end{array}$ \\
\hline $\begin{array}{l}\text { (1) Geometry } \\
\text { arrangement }\end{array}$ & + & ++ & $X$ & & Brief \\
\hline $\begin{array}{l}\text { (2) Furniture } \\
\text { arrangement }\end{array}$ & + & + & $X$ & $\bigcirc$ & Brief \\
\hline $\begin{array}{l}\text { (3) Space } \\
\text { design }\end{array}$ & + & - & & $X$ & $X$ \\
\hline $\begin{array}{l}\text { (4) Architecture } \\
\text { design }\end{array}$ & + & -- & & $X$ & $\times$ \\
\hline \hline $\begin{array}{l}\text { (5) Real-world } \\
\text { design }\end{array}$ & - & --- & & & Intention \\
\hline
\end{tabular}

\section{Conclusions and suggestions}

By analyzing design protocols with different definition-degree assignments in different definition-degree environments, this research has revealed some characteristics of design problem in design cognition, which are different from what problem-solving theory suggests. Design problem always relates two or more of three aspects: form of production, meaning of form, and operation of design, and occurs in designers' cognition when these aspects are in some unsatisfied situations. It seems that there are concealed criterion behind the judgment of "unsatisfied": one is from design brief as those problem-solving theory discussed, the other is due to designers' intention. In the latter, a designer is not just an entity, which can use knowledge and heuristics to design, but also a self-devoted worker. The work of clarifying these differences in design problem 
aims not at any meaning of definition but at revealing the important thinking phenomenon about design problem, which may have evoked a particular thinking mechanism and need to be more considerations for understanding human design cognition.

\section{References}

[1] Akin, Ö: 1986, Psychology of Architectural Design, Pion Limited, London.

[2] Chiang, Y. and Wang, M., 2004,'The Eureka Structure in Design", Proceedings of the Seventeenth Conference on Architectural researches, Architectural Institute of the Republic of China, Taiwan.

[3] Eastman C., 1978, "Representation of design problems and maintenance of their structure", Artificial Intelligence and Pattern Recognition in Computer aided Design, Ed. J-C Latombe, North-Holland, New York, pp.335-366.

[4] Ericsson, K. A. and Simon, H. A., 1993, Protocol Analysis: verbal reports as data, Rev. ed., MIT Press.

[5] Lawson, Bryan, 1997, How Designers Think- The design process demystified, Architectural Press.

[6] Reitman, W. R., 1964, "Heuristic decision procedures, open constraints, and structure of ill-defined problems" in Human Judgments and Optimality, Eds. M. W. Shelly, G. L. Bryan, John Wily, New York, PP.282-325.

[7] Simon, H. A., 1973, "Structure of ill-defined problems", Artificial Intelligence 4, pp 181-201. 